\title{
Characterization of cytosolic forms of CTP : choline-phosphate cytidylyltransferase in lung, isolated alveolar tye II cells, A549 cell and Hep G2 cells
}

\author{
Paul A. Weinhold, Mary Ellen Rounsifer, Linda Charles and Douglas A. Feldman \\ Department of Biological Chemistry, University of Michigan, and Veterans Administration Medical Center, Ann Arbor, MI (U.S.A.)
}

(Received 27 March 1989)

(Revised manuscript received 19 July 1989)

Key words: CTP : choline-phosphate cytidylyltransferase; Cytidylyltransferase; Phosphatidylcholine synthesis; Isozyme structure; Enzyme aggregate

The subcellular forms of cytidylyltransferase (EC 2.7.7.15) in rat lung, rat liver, Hep G2 cells, A549 cells and alveclar Type II cells from adult rats were separated by glycerol density centrifugation. Cytosol prepared from lung, Hep $G 2$ cells, A549 cells and alveolar Type II cells contained two forms of the enzyme. These species were identical to the L-Form and H-Form isolated previously from lung cytosol by gel filtration. Liver cytosol contained only the L-Form. Rapid treatment of Hep G2 cells with digitonin released all of the cytoplasmic cytidylyltransferase activity. The released activity was present in both $\mathrm{H}$-Form and L-Form. The molecular weight of L-Form was determined from sedimentation coefficients and Stokes radius values to be $97690 \pm 10175$. Thus, the L-Form appears to be a dimer of the $M_{\mathrm{r}} 45000$ catalytic subunit. The $f / f^{\circ}$ value of 1.5 indicated that the protein molecule has an axial ratio of 10 , assuming a prolate ellipsoid shape. The estimated molecular weight of the H-Form was $284000 \pm 25000$. The H-Form was dissociated into L-Form by incubation of cytosol at $37^{\circ} \mathrm{C}$. Triton X-100 $(0.1 \%)$ and chlorpromazine $(1.0 \mathrm{mM})$ also dissociated the H-Form into L-Form. Western blot analysis indicated that both forms contained the catalytic subunit. An increase in $M_{\mathrm{r}} 45000$ subunit coincided with the increase in cytidylyltransferase activity in L-Form, which resulted from the dissociated of H-Form. The L-Form was dependent on phospholipid for activity. The H-Form was active without lipid. Phosphatidylinositol was present in the H-Form isolated from Hep G2 cells. The phosphatidylinositol dispersed when the H-Form was dissociated into L-Form. Phosphatidylinositol and phosphatidylglycerol cause L-Form to aggregate into a form similar to H-Form. Phosphatidylcholine / oleic acid (1:1 molar ratio) and oleic acid also aggregated the L-Form. Phosphatidylcholine did not produce aggregation. We conclude that the H-Form is the active form of cytidyIyltransferase in cytoplasm. The H-Form appears to be a lipoprotein consisting of an apoprotein (L-Form dimer of the $M_{\mathrm{r}} 45000$ subunit) complexed with lipids. A change in the relative distribution of $\mathrm{H}-$ Form and L-Form in cytosol would alter the cellular activity and thus may be important in the regulation of phosphatidylcholine synthesis.

\section{Introduction}

CTP: choline phosphate cytidylyltransferase catalyzes the formation of CDP-choline from choline phosphate and CTP. Cytidylyltransferase is a major regulatory enzyme in the biosynthesis of phosphatidylcholine. Although numerous studies have provided insight into the mechanisms which regulate cytidylyltransferase activity (reviewed in Refs. 1,2) a clear understanding of these processes remains to be achieved.

Correspondence: P.A. Weinhold, Medical Research, VA Medical Center, 2215 Fuller Road, Ann Arbor, MI 48105, U.S.A.
A wide variety of experimental approaches have consistently shown that increased incorporation of radiolabelled choline into phosphatidylcholine is correlated with an increase in membrane cytidylyltransferase activity [3-23]. The increased cytidylyltransferase activity in isolated microsomes has been proposed to result from the translocation of inactive cytidylyltransferase in the cytosol to membranes, where it becomes active $[1,24]$. However, in many cases, the published data do not support translocation as the sole mechanism of activation because the increased membrane activity was not matched by a decreased activity in the cytosol [14-23]. In other cases, the cytidylyltransferase activity increased in both cytosol and microsomes [14,19,20,22]. Furthermore, hormonal modulation of phosphatidylcholine 
synthesis during lung development caused an increase in cytosolic cytidylyltransferase activity without changes in the membrane activity $[20,25,26]$. Although an increase in membrane cytidylyltransferase activity appears to be a significant component of the enzyme regulation, the activation or interconversion of cytosolic forms of cytidylyltransferase may also contribute to the overall control mechanisms.

The purpose of the present study was to characterize in more detail the cytosolic forms of cytidylyltransferase and to examine the interconversion of cytosolic forms. These studies were facilitated by the development of a reproducible method to separate cytosolic forms of cytidylyltransferase which was applicable to relatively small amounts of cytosolic activity. This method involved the separation of cytosols or postmitochondrial supernatants by glycerol density centrifugation.

\section{Materials and Methods}

Cell culture. Hep $\mathbf{G 2}$ cells, a cell line derived from a human hepatoma, were obtained from Dr. Thomas Gelehrter, University of Michigan with permission from Dr. Barbara Knowles, the Wistar Institute, Philadelphia, PA. Cells were cultured in DMEM (Dulbecco's Modified Eagle Medium, GIBCO) containing $10 \%$ fetal bovine serum, and $1 \%(\mathrm{v} / \mathrm{v})$ antibiotic/antimycotic solution (penicillin 10000 units $/ \mathrm{ml}$, fungizone $(25$ $\mu \mathrm{g} / \mathrm{ml})$ and streptomycin $(10 \mathrm{mg} / \mathrm{ml})$, obtained from GIBCO, Grand Island, NY). A549 cells, a cell line derived from a human lung adenoma, were obtained from Dr. Jacob Finkelstein. University of Rochester Medical School, Rochester, NY and were cultured in DMEM containing $10 \%$ fetal bovine serum and $1 \%$ antibiotic/antimycotic solution. Alveolar Type II cells were isolated from rat lung exactly as described by Dobbs et al. [27]. Isolated cells were cultured in DMEM containing $10 \%$ fetal calf serum and $1 \%$ antibiotic/ antimycotic solution. The cells which attached to the culture dish during the first $24 \mathrm{~h}$ were used for experiments. The cells were 88-90\% Type II cells as judged by Toluidine blue staining which enabled clear identification of lamellar body containing cells and by binding of Machura pomifera lectin labelled with fluorescein (E-Y Laboratories, San Mateo, CA) [28]. Toluidine blue staining was done by adding Toluidine blue in phosphate-buffered saline $(0.1 \mathrm{ml}$ of a $1.0 \%$ Toluidine blue in $1.0 \%$ sodium borate diluted in $5.0 \mathrm{ml}$ of phosphatebuffered saline) to cell cultures. The cultures were incubated at room temperature for about $\mathbf{1 0} \mathrm{min}$. The Toluidine blue was concentrated in the lamellar bodies which were clearly distinguished by phase contrast microscopy.

Preparation of subcellular fractions. Rats (male, Sprague-Dawley; 200-225 g) were purchased from
Charles River. The liver or lung was perfused free from blood with isotonic saline, placed in a beaker on ice and minced with scissors. The tissue was homogenized in a volume of $0.15 \mathrm{M} \mathrm{KCl} / 50 \mathrm{mM}$ imidazole- $\mathrm{HCl} / 1.0 \mathrm{mM}$ EDTA (pH 7.4) (buffer A) equal to 4-times the weight of tissue. Homogenization was performed in a glassTeflon Potter-Elvehjem homogenizer. The homogenate was centrifuged at $1000 \times \mathrm{g}$ for $10 \mathrm{~min}$. The resulting supernatant was centrifuged at $20000 \times g$ for $20 \mathrm{~min}$ to obtain a postmitochondrial supernatant. Microsomes were isolated from the postmitochondrial supernatant by centrifugation at $100000 \times \mathrm{g}$ for $60 \mathrm{~min}$. All steps were performed at $4^{\circ} \mathrm{C}$.

Cells were scraped from the culture dish with a Teflon cell scraper (Costar, Cambridge, MA) in Dulbecco's phosphate buffered saline (GIBCO). The cells were collected by centrifugation and the cell pellet was homogenized in buifer $A$ by sonication (three $15 \mathrm{~s}$ bursts in an ice/water bath). The volume of buffer $A$ used for homogenization was 4-times the estimared volume of the cell pellet. The homogenate was centrifuged at $1000 \times \mathrm{g}$ for $10 \mathrm{~min}$ to remove any unbroken cells. The supernatant was placed in $1.0 \mathrm{ml}$ Eppendorf tubes which were then placed in polycarbonate ultracentrifuge tubes filled with buffer as described by Murthy and Bharucha [29]. Cytosolic and particulate fractions were prepared from the supernatant by centrifugation at $100000 \times \mathrm{g}$ for $60 \mathrm{~min}$ in a Beckman L8-70m ultracentrifuge using a Ti-70.1 rotor.

Enzyme activity. Cytidylyltransferase activity was determined as previously described [30]. The activity in gradient fractions from cell cytosols was measured using a $300 \mu \mathrm{l}$ assay volume so that $150 \mu 1$ sample volumes could be used. Since the CDP-choline from the entire reaction is recovered by charcoal adsorption, this permitted us to increase the volume of fractions assayed without loss of sensitivity. This assay was able to detect activities of $0.03 \mathrm{nmol} / \mathrm{min}$ per fraction. All activities were determined with $500 \mu \mathrm{M}$ phosphatidylcholine-oleic acid $(1: 1$ molar ratio) in the assay mixture unless stated otherwise. Choline phosphotransferase activity was measured as described previously using dioleoylglycerol/phosphatidylglycerol/Tween 20 microemulsion as substrate [31].

Density gradient centrifugations. Glycerol gradients (12 ml, linear 8 to $40 \%(\mathrm{v} / \mathrm{v})$ in buffer $A)$ were prepared with a two-chamber gradient mixer. $A$ volume equal to the sample volume was removed from the top and replaced with sample. Centrifugation was performed in a SW 41 rotor at $40000 \mathrm{rpm}$ for $14 \mathrm{~h}$ at $4^{\circ} \mathrm{C}$. The bottom of the tube was punctured and fractions were collected. The pellet at the bottom of the tube was suspended in $0.5 \mathrm{ml}$ of buffer $\mathrm{A}$ by repeated extrusion through a $100 \mu 1$ Hamilton syringe. Aliquots were removed from each fraction for the measurement of cytidylyltransferase activity. Protein was determined in 
each fraction using the Bradford assay [32]. In some experiments cholinephosphotransferase activity was determined in each fraction as a marker for microsomes.

Standard proteins were run on separate gradients and their positions in the gradient were located by protein assay. Sedimentation coefficients $\left(s_{20, w}\right)$ relative to the standard proteins were determined according to the method of Martin and Ames [33].

Gel filtration. Gel filtration was performed with a $2.6 \times 95 \mathrm{~cm}$ column of Bio-Gel A1.5m (Bio-Rad). The column was equilibrated and eluted with buffer $A$. Samples $(0.5 \mathrm{ml})$ were applied. The column was eluted at a flow rate of $8 \mathrm{ml} / \mathrm{h}$. Calibration of the column was done with a gel filtration standard mixture (Dio-Rad) which contained thyroglobulin $\left(R_{\mathrm{s}}=8.6 \mathrm{~nm}\right)$, gamma globulin $\left(R_{\mathrm{s}}=5.5 \mathrm{~nm}\right)$, ovalbumin $\left(\boldsymbol{R}_{\mathrm{s}}=2.8 \mathrm{~nm}\right)$ and myoglobin $\left(R_{\mathrm{s}}=2.0 \mathrm{~nm}\right)$. Stokes radii $\left(\boldsymbol{R}_{\mathrm{s}}\right)$ were determined from linear plots of $\left(K_{\mathrm{d}}\right)^{1 / 3}$ vs. $\boldsymbol{R}_{\mathrm{s}}$.

Calculation of molecular weights. Molecular weights and frictional ratios were calculated from Stokes radius and sedimentation coefficients as described by Siegel and Monty [34]. We used a value of $0.74 \mathrm{ml} / \mathrm{g}$ for the partial specific volume [35]. We assumed a value of 0.2 $g$ of solvent/g of protein for the solvation factor [36]. Axial ratios for a prolate ellipsoid were derived from values given by Schachman [37].

Electrophoresis and electroblotting of cytidylyltransferase. Gradient fractions were analyzed by SDS-polyacrylamide electrophoresis (SDS-PAGE) [38]. Aliquots were precipitated with $10 \%$ trichloracetic acid. The precipitate was dissolved in sample buffer (62.5 mM Tris/ $1 \%$ SDS/10\% glycerol (pH 6.8)) and the excess trichloroacetic acid was neutralized with $\mathrm{NH}_{3}$ (air delivered from a flask containing concentrated $\mathrm{NH}_{4} \mathrm{OH}$ ). The samples were boiled for $5 \mathrm{~min}$ in the presence of $10 \% 2$-mercaptoethanol. Separation was achieved on $10 \%$ gels with a $4 \%$ stacking gel.

After SDS-PAGE, the proteins were electroblotted onto immobilon membranes (Millipore) using the blotting system described by Small et al. [39]. This blotting system allowed for the sensitive immunodetection of cytidylyltransferase from tissue and cell fraction. The more standard blotting methods did not produce immunopositive bands for the $M_{\mathrm{r}} 4500$ n cytidylyltransferase subunit.

Immunodetection of Western blots. Antiserum against purified cytidylyltransferase was raised in rabbits. Cytidylyltransferase was purified from rat liver as previously described [40]. Anti-cytidylyltransferase IgG was isolated from the antiserum using a cytidylyltransferase-Affiprep affinity column (Bio-Rad). Both the antiserum and the purified IgG completely titrated cytidylyltransferase activity in cytosol preparations from liver and lung. The detailed characterization of the antibody will be published subsequently.
Blots were blocked at $40^{\circ} \mathrm{C}$ for $2 \mathrm{~h}$ in $5 \%$ bovine serum albumin (BSA) dissolved in $25 \mathrm{mM}$ Tris/150 $\mathrm{mM} \mathrm{NaCl} / 0.05 \%$ Tween 20 (TST). The blots were then incubated at room temperature for $2 \mathrm{~h}$ with a dilution of anti-cytidylyltransferase IgG in $1.0 \%$ BSA in $1 \mathrm{~S}^{\mathrm{N}}$. After washing in $0.1 \%$ BSA in TST, the blot was incubated with goat inti-rabbit IgG-alkaline phosphatase (Sigma) at a dilution of 1:4000 in 1.0\% BSA dissolved in TST. The blot was washed three times with TST and developed with 5-bromo-4-chloro-3-indolylphosphate (BCIP)-nitroblue tetrazolium (NBT) as described in the Bio-Rad instruction protocol.

\section{Results}

Distribution of cytidylyltransferase activity in liver and lung

The $20000 \times g$ supernatants (postmitochondrial supernatants) from liver and lung were separated by glycerol density gradient centrifugation, Fig. IA. Cytidylyltransferase activity in lung was separated into three forms; two types of soluble activity (peaks at 9.0 $\mathrm{ml}$ and at 5.0-6.5 ml) and microsomal activity (pelleted at the bottom of the tube, indicated as 0 ). Over $98 \%$ of the activity of choline phosphotransferase, a microsomal enzyme, was recovered at the bottom of the gradient (data not shown). The separation of lung cytosol $(100000 \times g$ supernatant) by glycerol density centrifugation resulted in the appearance of two peaks of activity within the gradient, Fig. 1B. There was no activity at the bottom of the tube when cytosol was used. This comparison demonstrated that the cytidylyltransferase activity at the bottom of the post-mitochondrial gradients was microsomal-bound enzyme.

We reported previously that adult rat lung contains a high- $M_{\mathrm{r}}$ (H-Form) and a lower- $M_{\mathrm{r}}$ (L-Form) species of cytidylyltransferase in cytosol $[41,43]$. These forms were classified according to their elution from Bio-Gel A5.0m gel-filtration columns. In order to establish that the forms isolated by glycerol density centrifugation were the same as those isolated by gel filtration, we applied $\mathrm{H}$ and $\mathrm{L}$ Forms isolated by gel filtration onto glycerol density gradients. The H-Form activity peaked at $6.2 \mathrm{ml}$ and L-Form peaked at $9.2 \mathrm{ml}$. In addition, fractions between 5.5 and $6.5 \mathrm{ml}$ and 8.6 and $9.8 \mathrm{ml}$ from glycerol gradients of lung cytosol samples were combined and analyzed by gel filtration. The $8.6-9.8 \mathrm{ml}$ pool eluted as L-Form and the $5.5-6.5 \mathrm{ml}$ pool eluted as H-Form. Thus, the forms isolated by glycerol density centrifugation were identical to those previously isolated by gel filtration.

Postmitochondrial supernatant and cytosol from liver contained only L-Form cytidylyltransferase, Fig. 1A and $\mathrm{B}$. Although a small amount of high-molecularweight form of cytidylyltransferase has been reported to be present in liver cytosol preparations when separated 

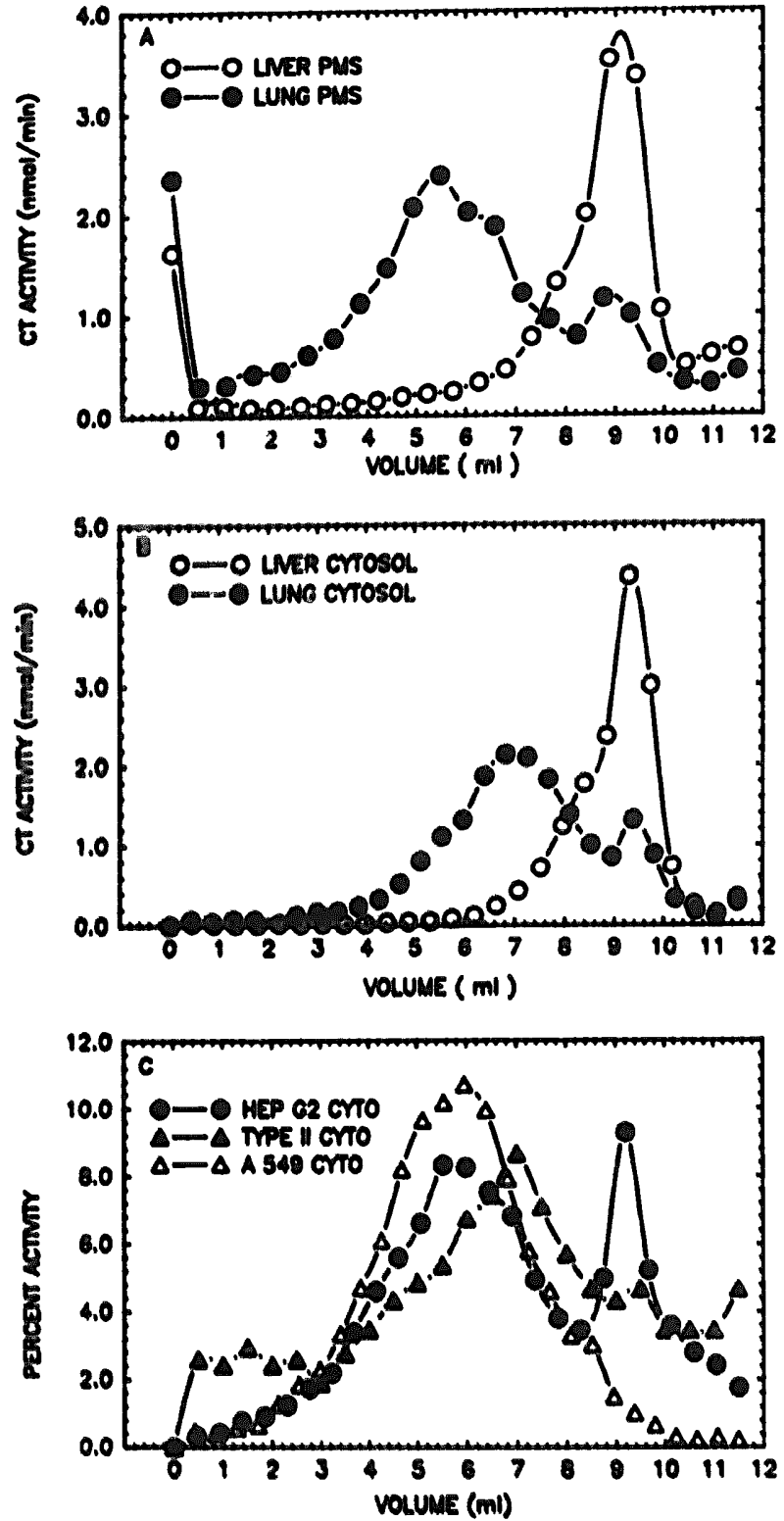

Fig. 1. Separation of subcellular forms of cytidylyltransferase by glycerol density centrifuzations. Fraction 0 represents the activity recovered at the bottom of the gradient tube. (A) The $20000 \times g$ supernatant (postmitochondrial supernatant, PMS) from rat liver or lung was separated on glycerol gradients. In (B) and (C) cytosol (100000 $\times$ supernatants) was separated on glycerol gradients.

by gel-filtration chromatography $[42,43]$, we found no evidence for a high- $M_{r}$ form in the glycerol gradients.

The above experiments used subcellular preparations isolated from homogenates prepared in buffer $A$. The homogenization of lung in different buffers did not significantly alter the gradient profiles of cytidylyltransferase in cytosolic preparations. Gradient profiles of cytosol prepared from lung by homogenization in $\mathbf{5 0}$ $\mathrm{mM}$ Tris/0.25 M sucrose/2 mM EDTA were similar to those in Fig. 1 (data not shown). Lung was also homogenized in $50 \mathrm{mM}$ Tris buffer containing either no $\mathrm{KCl}, 50 \mathrm{mM} \mathrm{KCl}$ or $150 \mathrm{mM} \mathrm{KCl}$. Gradient profiles of the cytosolic fractions were similar to those in Fig. 1 (data not shown). The amount of total activity was much lower in the cytosol from the homogenates prepared without $\mathrm{KCl}$. The total activity increased in the $50 \mathrm{mM} \mathrm{KCl}$ cytosol and was the highest in the $150 \mathrm{mM}$ $\mathrm{KCl}$ cytosol. However, the relative amounts of the two forms of cytidylyltransferase was similar in all three cytosolic preparation. The use of $\mathrm{NaCl}$ instead of $\mathrm{KCl}$ did not change the results.

The higher-molecular-weight form is prominent in cytosols prepared from lung. Lung contains pulmonary surfactant, a lipoprotein complex which includes relatively high amounts of phosphatidylcholine and phosphatidylglycerol. We examined the possibility that the higher-molecular-weight form was an artifact due to binding of cytosolic cytidylyltransferase to surfactant components derived from alveolar surfactant during homogenization. Extensive lavage of adult rat lung (ten times with $10 \mathrm{ml}$ of isotonic saline) was performed prior to homogenization in buefer $A$. This did not change the gradient profile of cytidylyitransferase activity in the cytosolic preparation (data not shown).

\section{Distribution of cytidylyltransferase activity in cells}

Isolated alveolar Type II cells, Hep G2 cells and A549 cells contained both cytosolic forms of cytidylyltransferase, Fig. 1C. The high-molecular-weight form predominated, particularly in A549 cells and alveolar Type II cells. The total activity in homogenates of A549 cells and Hep G2 cells was $9.9 \pm 1.6 \mathrm{nmol} / \mathrm{min}$ per $\mathrm{mg}$ DNA $(n=6)$ and $12.9 \pm 1.9 \mathrm{nmol} / \mathrm{min}$ per mg DNA $(n=4)$, respectively. Cytosols from A549 cells contained $43 \pm 3 \%$ of the total activity. Cytosols from Hep G2 cells contained $56 \pm 0.5 \%$ of the total activity. In Hep G2 and A549 cell lines more than 90\% of the cytidylyltransferase activity appeared to be either associated with microsomal membranes or in a high-molecular-weight complex in cytosol fractions.

\section{Distribution of cytidylyltransferase activity released from cells by digitonin}

Mackall et al. [49] developed a procedure for the rapid release of cytoplasmic enzymes from cultured cells with minimal organelle disruption. This method has been used to demonstrate translocation of cytidylyltransferase in HeLa cells [7] and in Chinese hamster ovary cells [10]. We applied this method to Hep G2 cells and exanined the soluble forms of cytidylyltransferase released. Cells were harvested from $100 \mathrm{~mm}$ dishes by gentle scraping and collected by centrifugation at $800 \times$ g. A $1 \mathrm{~min}$ exposure of the cell pellet to $0.8 \mathrm{mg} / \mathrm{ml}$ digitonin in buffer $\mathbf{A}$ followed by centrifugation at $9000 \times g$ for $10 \mathrm{~min}$ released $10.5 \pm 0.03 \mathrm{nmol} / \mathrm{min}$ per dish $(n=3)$ of cytidylyltransferase activity. The pellet was processed further by sonication in buffer $A$. The sonicate was centrifuged sequentially at $2000 \mathrm{rpm}$ for 10 min to give a low-speed pellet, $10000 \times g$ for $20 \mathrm{~min}$ to 


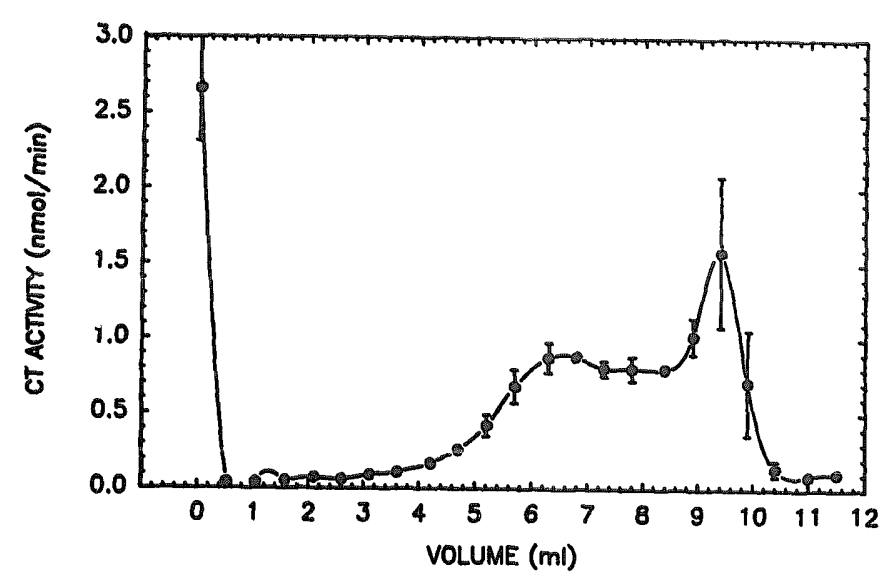

Fig. 2. Glycerol density gradient analysis of cytidylyltransterase activity released by digitonin treatment of Hep $\mathrm{G} 2$ cells. The profile is the average of three independent experiments. Each experiment used the combined cells from five dishes $(100 \mathrm{~mm})$ of Hep $\mathrm{G} 2$ cells. Cells were plated at $2 \cdot 10^{6}$ cells per dish and cultivated 4 days. The error bars represent the standard deviations for the three experiments.

give a $10000 \times g$ pellet and $100000 \times g$ for $60 \mathrm{~min}$ to give a microsomal pellet and a supernatant. The sum of the activity in the three particulate pellets (low-speed, $10000 \times g$ and $100000 \times g$ ) was $3.8 \pm 0.03 \mathrm{nmol} / \mathrm{min}$ per dish. There was only $0.21 \pm 0.05 \mathrm{nmol} / \mathrm{min}$ per dish in the high-speed supernatant. Thus, the digitonin treatment released essentially all of the cytoplasmic enzyme activity. Cholinephosphotransferase activity was also determined as a marker for endoplasmic reticulum membranes. Less than 5\% of the total cholinephosphotransferase activity was released by digitonin treatment. Gradient density centrifugation of the digitonin supernatant showed that both forms of cytidylyltransferase were present (Fig. 2). In addition, there was some activity at the bottom of the gradient tube (fraction 0 in Fig. 2). This activity accounted for about $20 \%$ of the total activity released by digitonin. All of the cholinephosphotransferase activity in the digitonin supernatant was recovered at the bottom of the tube. Thus the

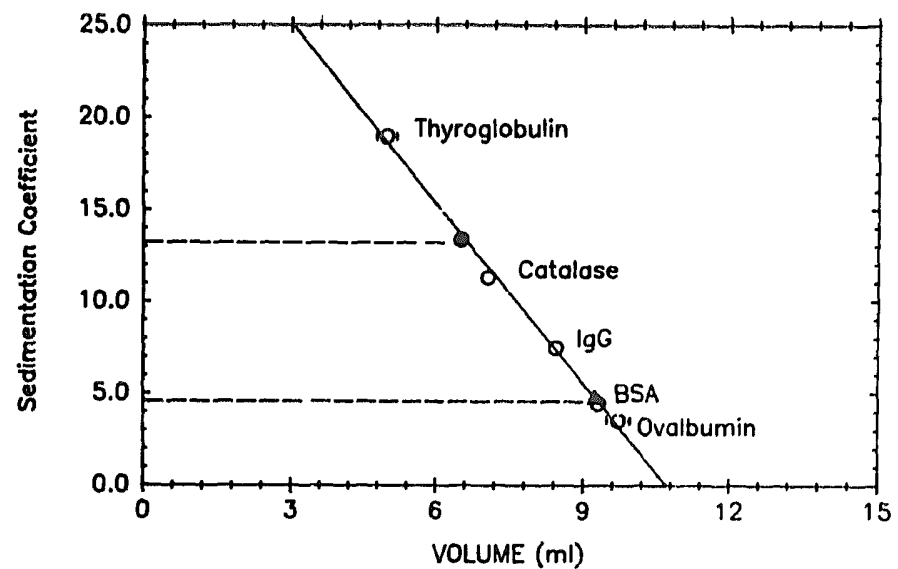

Fig. 3. The determination of sedimentation coefficients for the cytidylyltransferase forms separated by glycerol density centrifugations. and $\Delta$ represent the position of cytidylyltransferase forms in the gradient. pelleted material is probably a small amount of membrane fragments. The results described above were obtained from three separate experiments. It is noteworthy that $73 \%$ of the total cytidylyltransferase was released by digitonin compared to $56 \%$ of the total activity recovered in cytosols prepared by differential centrifugation of cell sonicates. The lower recovery could be due to binding of soluble cytidylyltransferase to membranes after the cells were broken. Since digitonin treatment releases soluble enzyme without extensive damage to intracellular membranes, enzyme binding to membrane fragments would be less likely.

\section{Calibration of glycerol gradients and determination of molecular weights}

Protein standards were separated on the glycerol gradients. A plot of sedimentation coefficients versus
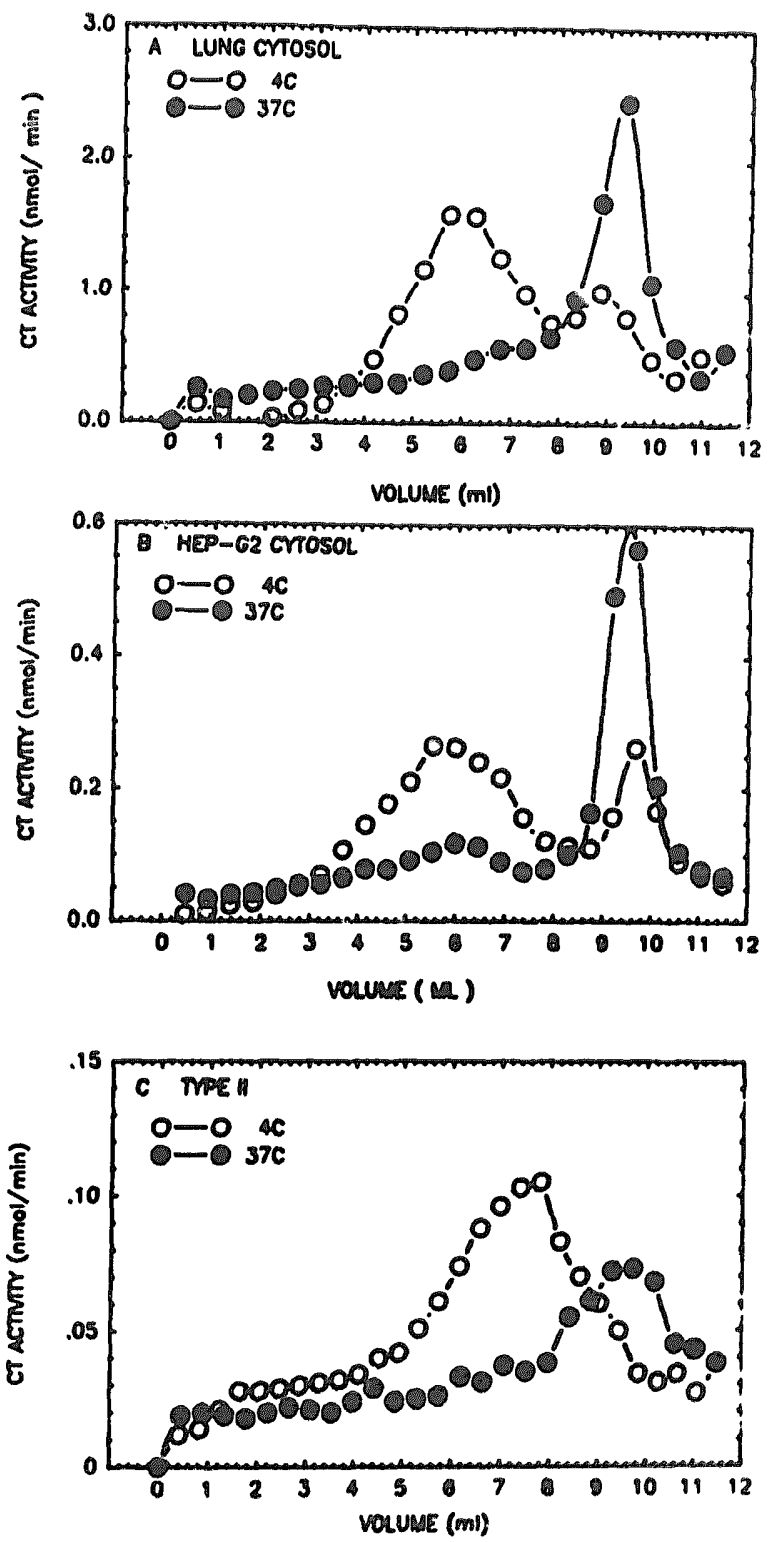

Fig. 4. The conversion of the H-Form cytidylyltransferase to L-Form cytidylyltransferase preparations. Cytosols were incubated at $37^{\circ} \mathrm{C}$ for $15 \mathrm{~min}$ or kept at $4^{\circ} \mathrm{C}$. 


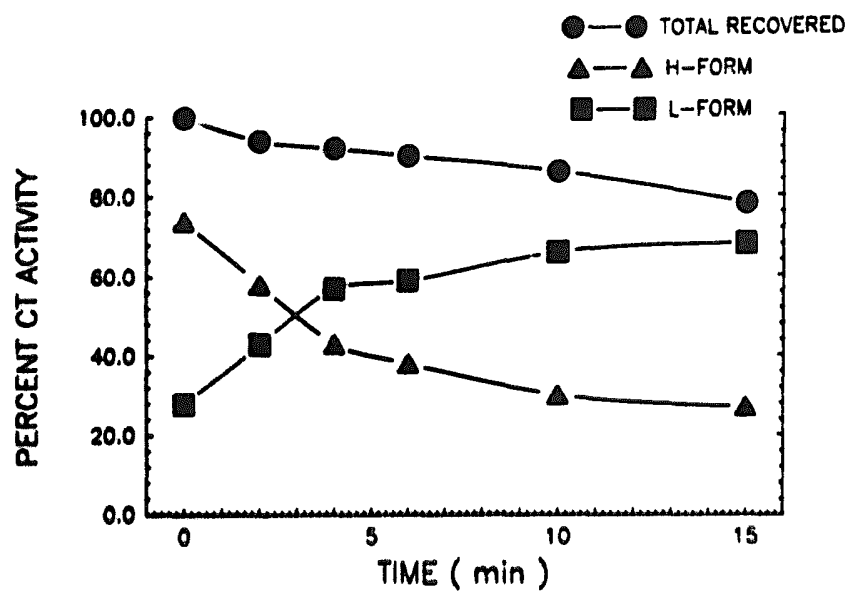

Fig. 5. The time dependency of the dissociation of H.Form to L.Form. The relative amounts of H.Form and L.Form were determined at each time point by fractionation of cytosols by glycerol density centrifugation. Incubation was performed at $37^{\circ} \mathrm{C}$ for the designated time and then rapidly cooled in an ice-bath.

the location on the gradients is shown in Fig. 3. Three independent analyses of the separation of the standards were performed. The relative positions of the standards were similar for the three experiments. The sedimentation coefficients for the two forms of cytidylyltransferase in lung cytosol were determined to be $4.8 \pm$ $0.5 \mathrm{~S}$ and $13.4 \pm 1.2 \mathrm{~S}(n=9)$. A Stokes radius of $48 \bar{\AA}$ was determined for the $4.8 \mathrm{~S}$ form by gel filtration chromatography. The molecular weight of the $4.8 \mathrm{~S}$ form was calculated to be $97690 \pm 10175$. The $f / f^{\prime}$ was 1.5. Assuming a prolate ellipsoid, an axial ratio of 10 was obtained from tables given in Ref. 37. Thus, the $4.8 \AA$ form (L-Form) appears to be an elongated molecule. An approximate molecular weight of $284000 \pm$ 25000 was obtained for the H-Form by glycerol gradient centrifugation using a plot of molecular weight of standard proteins versus the migration distance in the gradients. The molecular weight of the L-Form, estimated similarly by density gradient centrifugation, was 90000, which is similar to the calculated molecular weight.

\section{Conversion of $\boldsymbol{H}$-Form to $\mathbf{L}$-Form}

A 15 min incubation at $37^{\circ} \mathrm{C}$ of cytosol preparations from lung, Hep $\mathbf{G 2}$ cells and alveolar Type II cells dissociated the H-Form into L-Form (Fig. 4). The dissociation was time dependent (Fig. 5). Approximately

Fig. 6. Western blot analysis of glycerol gradient fractions from lung cytosol kept on ice (A), incubated at $37^{\circ} \mathrm{C}$ for $15 \mathrm{~min}$ (B) and from liver cytosol kept at $4^{\circ} \mathrm{C}$ (C). A $50 \mu \mathrm{l}$ sample from fractions at the various gradient volumes were mixed with $50 \mu$ l of SDS sample buffer and separated by SDS.PAGE on a $10 \%$ gel. The amount of cytidylyltransferase activity (CT activity) in the $50 \mu$ l aliquot is represented by the bar graph. The CT activity is plotted is $\mathrm{nmol} / \mathrm{min}$. half of the H-Form dissociated to L-Form in $4 \mathrm{~min}$. The sum of the activity in all forms decreased by less than $10 \%$ during this $4 \mathrm{~min}$ incubation, indicating that the
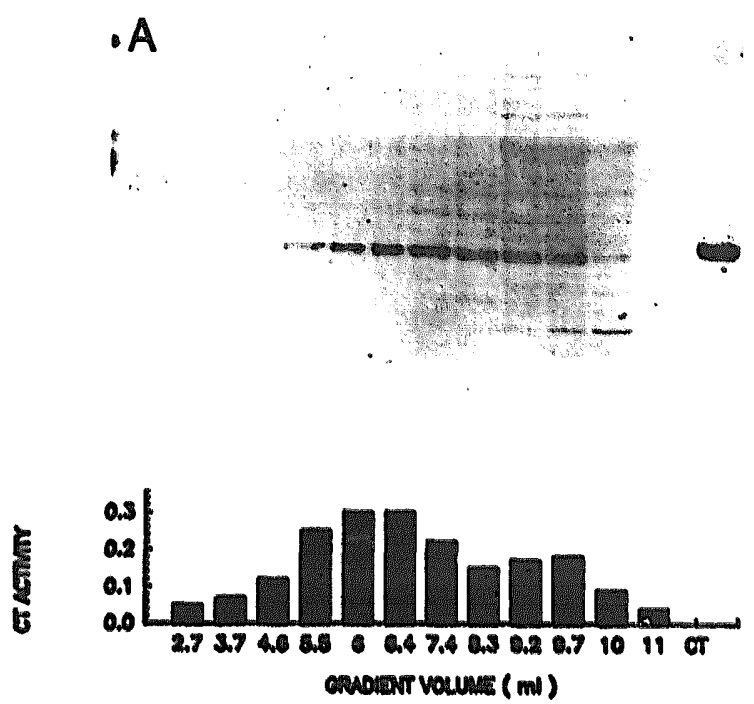

B

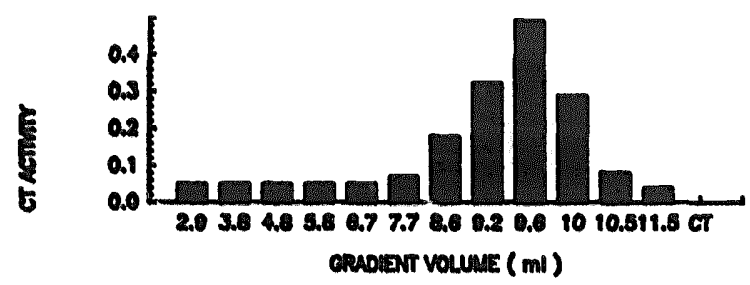

C

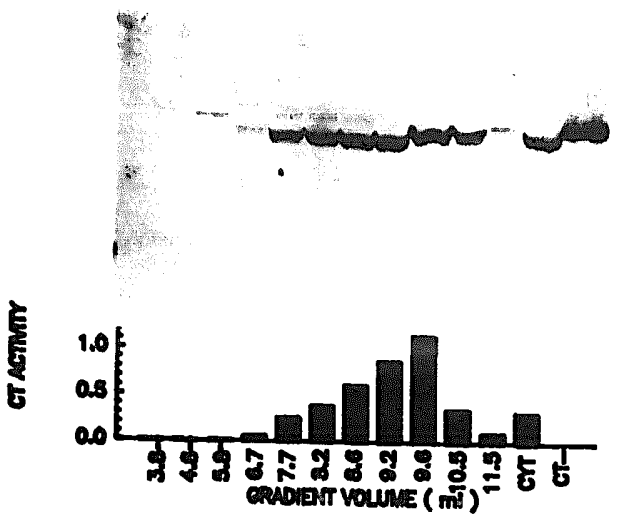



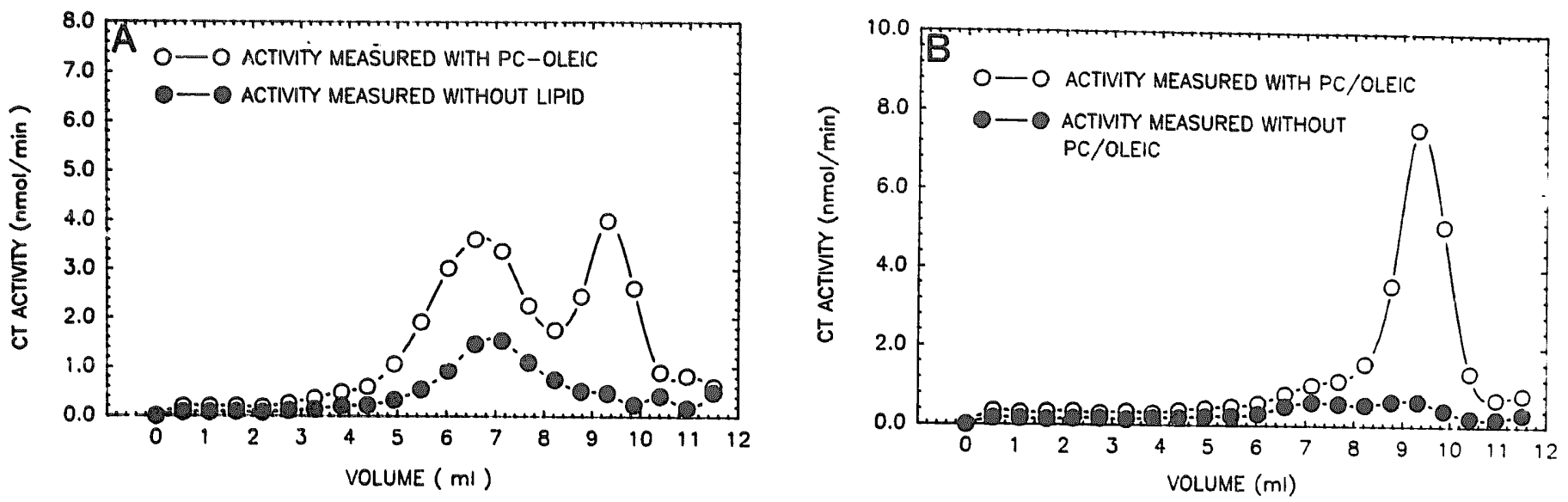

Fig. 7. The lipid requirement for cytidylyltransferase activity in the H-Form and L-Form. Activity in the fraction was determined either without lipid added to the assay or with $500 \mu \mathrm{M}$ phosphatidylcholine-oleic acid vesicles $(1: 1$ molar ratio). The vesicles were prepared by sonication and the concentration refers to the amount of phosphatidylcholine. (A) Lung cytosol at $4^{\circ} \mathrm{C}$; (B) lung cytosol incubated at $37^{\circ} \mathrm{C}$ for 15 min before application to the gradient.

decrease in activity in the H-Form was not due to an inactivation of enzyme.

Western blot analysis of fractions from the gradients indicated that the shift in the sedimentation pattern of the enzyme activity was associated with a corresponding shift in the $M_{\mathrm{r}} 45000$ subunit of cytidylyltransferase (Fig. 6). The $M_{\mathrm{r}} 45000$ subunit of cytidylyltransferase also coincided with the enzyme activity in the gradient from liver cytosol, (Fig. 6).

The H-Form of cytidylyltransferase was partially active without the addition of lipid cofactors to the assay (Fig. 7A). The L-Form was essentially inactive in the absence of lipid cofactors. The L-Form released from the H-Form complex showed the same lipid dependence (Fig. 7B). The temperature and time dependency of the dissociation suggested that it may involve some type of enzymatic reaction. Proteinase activity appeared not to be involved because the addition of a mixture of proteinase inhibitors ( $2 \mathrm{mM} \mathrm{DMSF}, 5 \mu \mathrm{g} / \mathrm{ml}$ pepstatin, 0.1 $\mu \mathrm{g} / \mathrm{ml}$ tosyl chloromethylketone, $5 \mu \mathrm{g} / \mathrm{ml}$ antipain) did not prevent the dissociation. It appeared unlikely that protein phosphatase activity was involved, since the addition of $150 \mathrm{mM}$ potassium fluoride did not prevent the dissociation. The addition of $3 \mathrm{mM} \mathrm{ATP} / 10 \mathrm{mM}$ $\mathrm{Mg}^{2+}$ to the cytosol also did not alter the dissociation. Quinicrine, a phospholipase inhibitor, added at a final concentration of $4.0 \mathrm{mM}$ had no effect on the dissociation. Since $2 \mathrm{mM}$ EDTA was present in the cytosol preparation, it would seem unlikely that $\mathrm{Ca}^{2+}$ requiring phospholipases would be active. Nevertheless, we added $10 \mathrm{mM} \mathrm{Ca}^{2+}$ to the cytosol incubations and found this did not alter the dissociation. The addition of $10 \mathrm{mM}$ iodoacetamide or $20 \mathrm{mM}$ dithiothreitol did not prevent the dissociation. This suggests that exposed sulfhydryl groups are not involved. Since fatty acids have been demonstrated to promote the binding of cytidylyltransferase to microsomal membranes [24], we examined the effect of $200 \mu \mathrm{M}$ oleic acid and $2 \%$ bovine serum albumin (fatty acid free). Neither addition altered the conversion of H-Form to L-Form.

The H-Form complex was isolated from the gradient peak by ammonium sulfate precipitation. All of the activity was recovered in the precipitate at 20 to $40 \%$ saturation of ammonium sulfate. The H-Form isolated in this way remained intact as demonstrated by density
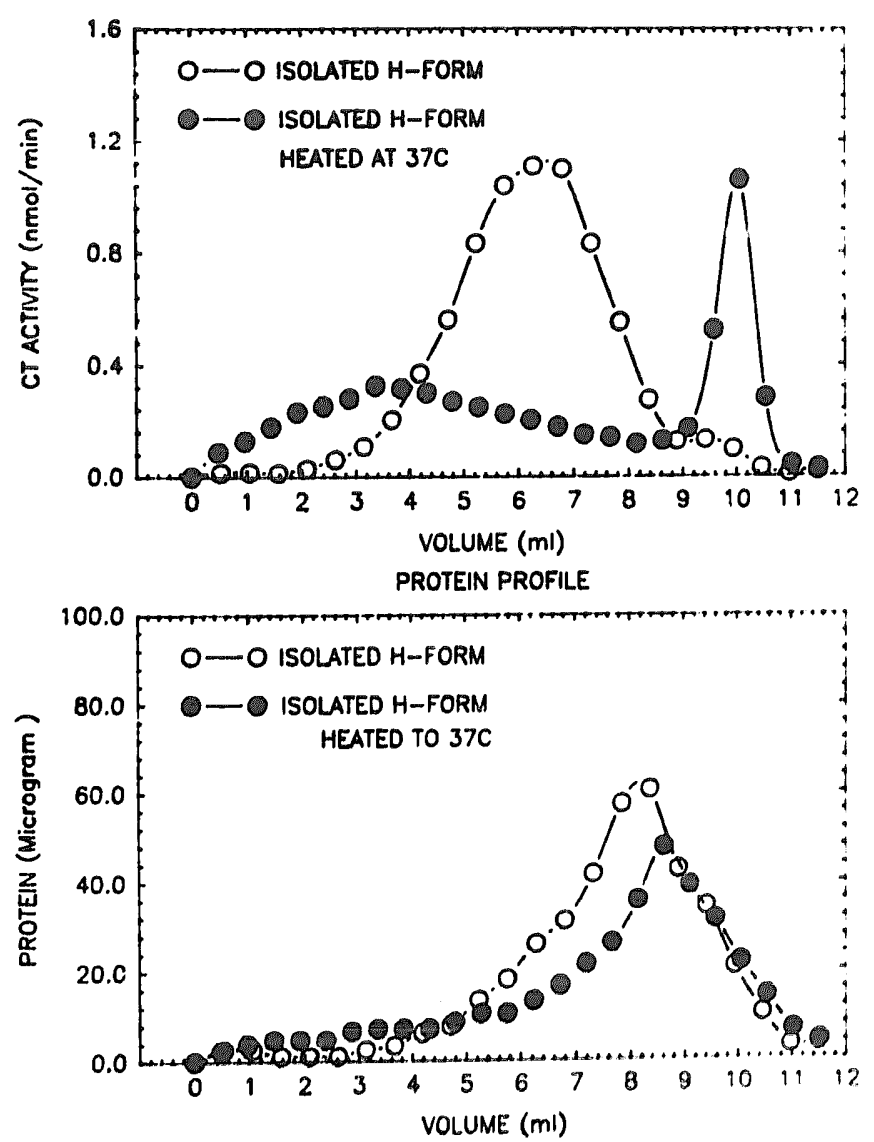

Fig. 8. Glycerol gradient analysis of H-Form isolated by ammonium sulfate preci-itation of gradient fractions. The isolated H-Form was either kept on ice or incubated at $37^{\circ} \mathrm{C}$ for $15 \mathrm{~min}$. 

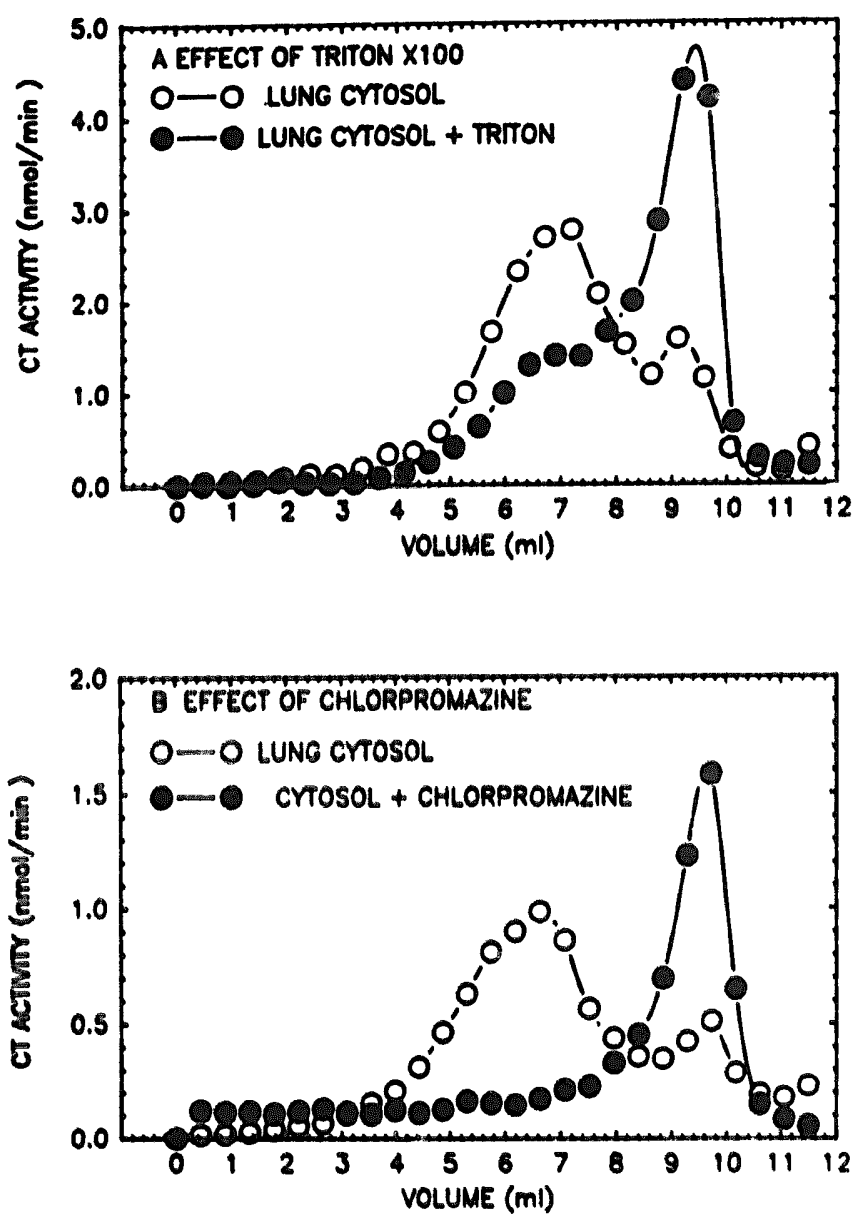

Fig. 9. The dissociation of H-Form cytidylyltransferase to L-Form cytidylyltransferase. Triton X-100 (0.1\%) or chlorpromazine (1 mM) was added to lung cytosol and then kept on ice for $30 \mathrm{~min}$ before application to the gradients.

gradient centrifugation, (Fig. 8A). Furthermore, the H-Form complex was separated from the bulk of the protein. This suggests that the H-Form complex is a minor protein component in the crude preparation. Incubation of the isolated $\mathrm{H}$-Form at $37^{\circ} \mathrm{C}$ for $15 \mathrm{~min}$ resulted in a dissociation of the complex into L-Form cytidylyltransferase (Fig. 8B). Some of the activity appeared to form larger aggregates. The protein profile was not altered by the $37^{\circ} \mathrm{C}$ incubation.

The addition of Triton X-100 (0.1\% final concentration) to lung cytosol at $4^{\circ} \mathrm{C}$ dissociated the H-Form to L-Form (Fig. 9A). A similar result was obtained with cytosol from Hep G2 cells (data not shown). The addition of chlorpromazine (1.0 $\mathrm{mM})$ to lung cytosol at $4^{\circ} \mathrm{C}$ also dissociated the H-Form into L-Form (Fig. 9B). The dissociation was accompanied by an apparent inhibition of activity when assayed without lipid, (Fig. 10). There was no inhibition when lipid was added to the assay. This result is consistent with a chlorpromazine-induced dissociation of an active H-Form into inactive L-Form. The concentration of chlorpromazine required in these experiments is substantially higher than the concentration reported to reduce choline incor-

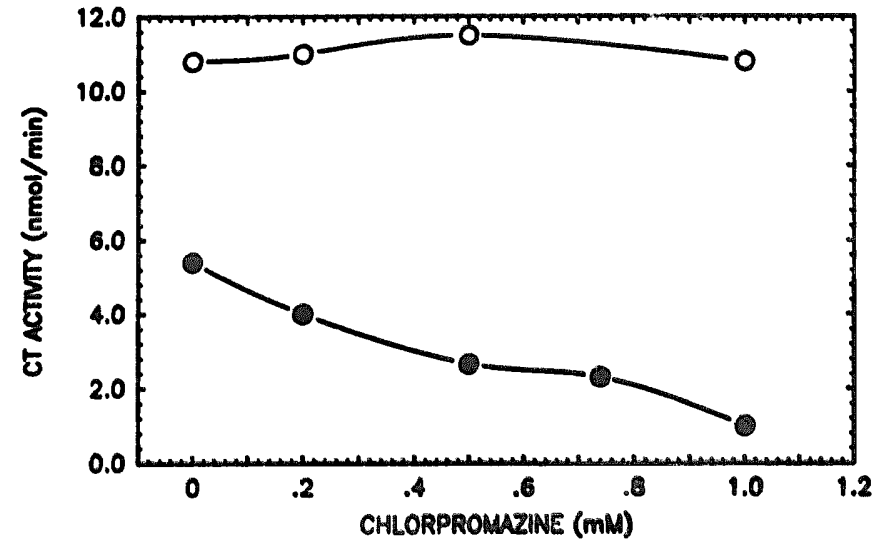

Fig. 10. The effect of chlorpromazine on cytidylyltransferase activity in lung cytosol. The cytosol-chlorpromazine mixtures were proncubated on ice for $30 \mathrm{~min}$. Aliquots were removed and assayed either without lipid (O) or with $500 \mu \mathrm{M}$ phosphatidylcholine-oleic acid vesicles (1:1 molar ratio) (O).

poration into phosphatidylcholine and cytidylyltransferase activity in HeLa cells [48]. Thus, it is uncertain whether the in vitro dissociation of H-Form can explain the effects of chlorpromazine in cell cultures.
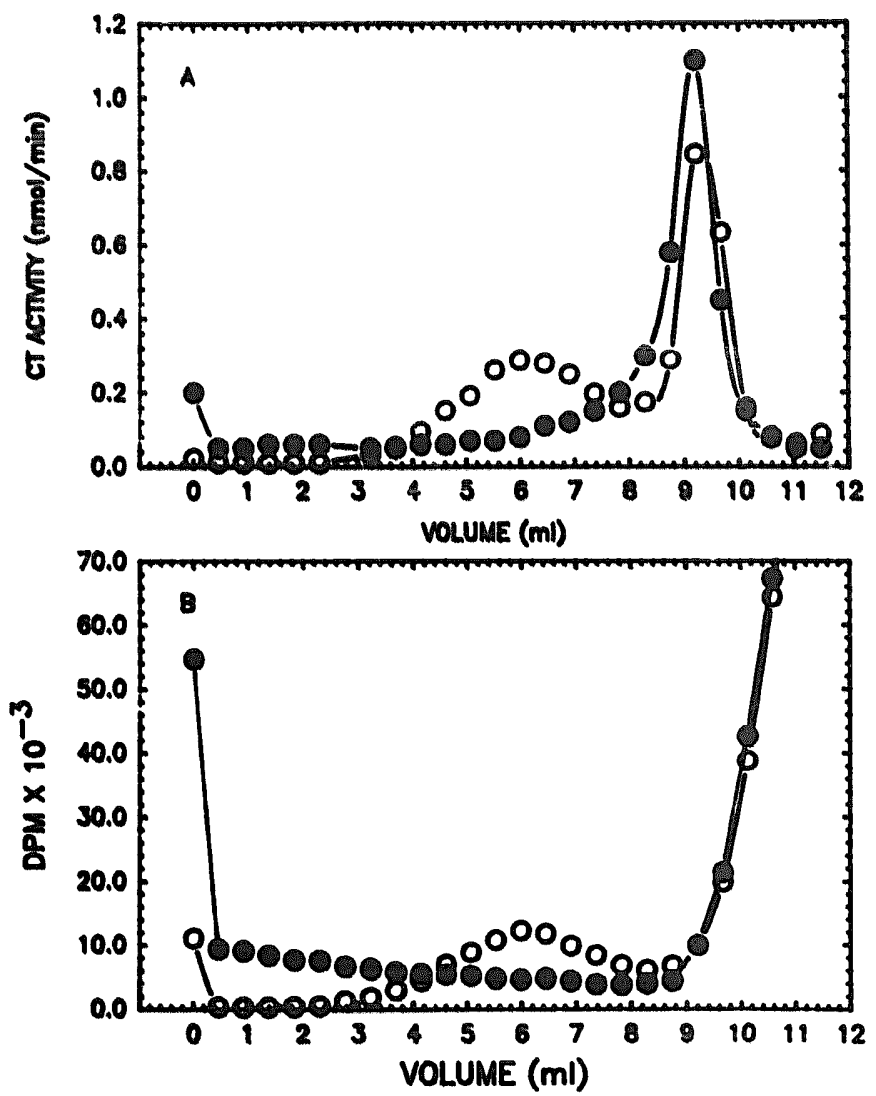

Fig. 11. The effect of chlorpromazine on the distribution of cytidylyltransferase activity and $\left[{ }^{3} \mathbf{H}\right]$ inositol in Hep G2 cytosol. Hep G2 cells were incubated with [ ${ }^{3} \mathrm{H}$ ]inositol for $24 \mathrm{~h}$. Cytosol was prepared and separated by glycerol density centrifugation. (A) The distribution of cytidylyltransferase activity in samples incubated at $4^{\circ} \mathrm{C}$ with 1.0 mM chlorpromazine ( $\theta$ ) compared to untreated controls $(O)$. (B) The distribution of $\left[{ }^{3} \mathrm{H}\right]$ inositol in samples incubated at $4^{\circ} \mathrm{C}$ with $1.0 \mathrm{mM}$ chlorpromazine $(\theta)$ compared to untreated controls $(0)$. 


\section{Lipid involvement in H-Form aggregate}

Evidence for the involvement of phospholipid in the H-Form aggregate was obtained from experiments with cultured Hep G2 cells. Hep G2 cells were cultured for $24 \mathrm{~h}$ in the presence of $2 \mu \mathrm{Ci} / \mathrm{ml}^{3} \mathrm{H}$ ]inositol. The cells were collected and homogenized. Cytosol $(2.0 \mathrm{ml})$ was prepared. Chlorpromazine was added to $1.0 \mathrm{ml}$ to give a final concentration of $1.0 \mathrm{mM}$. The two samples (control and chlorpromazine) were separated by density gradient centrifugation. The distribution of cytidylyltransferase activity in the gradient is shown in Fig. 11A. Chlorpromazine caused a dissociation of the H-Form to yield more L-Form enzyme. The distribution of radioactivity in the gradient is shown in Fig. 11B. The peak of radioactivity between 4.0 and $7.0 \mathrm{ml}$ in the gradient was extracted with chloroform/methanol (2:1). After the addition of water and separation of phases by centrif- ugation, all of the radioactivity was recovered in the chloroform phase. Thin-layer chromatography of the chloroform-soluble lipid indicated that the radioactivity was in phosphatidylinositol. Thus, phosphatidylinositol was present in the H-Form peak from the gradient. Chlorpromazine apparently dissociated the aggregate releasing the dimer $\mathbf{L}-\mathrm{Form}$ of cytidylyltransferase and the phosphatidylinositol. The dissociated phosphatidylinositol was recovered at the bottom of the gradient. Thin-layer chromatography of the lipid extract of the pellet at the bottom of the gradient indicated that the radioactivity was in phosphatidylinositol. The radioactivity at the top of the gradient was water-soluble and presumed to be $\left[{ }^{3} \mathrm{H}\right]$ inositol.

Further evidence for the involvement of lipid was obtained by in vitro studies with lung cytosol. The results of these experiments are shown in Fig. 12. The
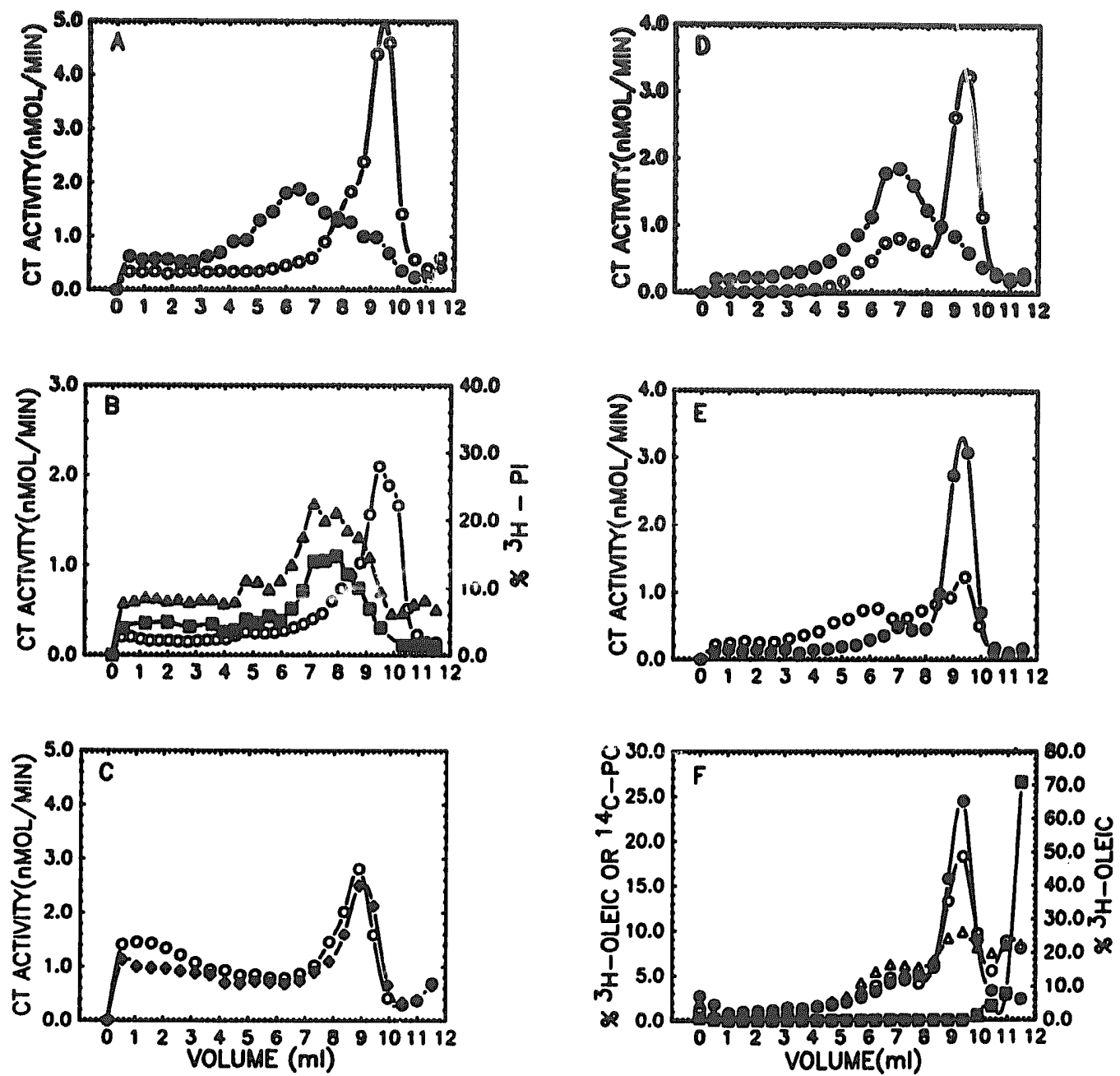

Fig. 12. The aggregation of L-Form by lipids. Lung cytosol was incubated at $37^{\circ} \mathrm{C}$ for $15 \mathrm{~min}$. The appropriate lipid was added after the incubated cytosol had been cooled on ice. The lipid-cytosol mixture was kept on ice for an additional 30 min and then applied to a glycerol gradient. The lipids were added from a $0.5 \mathrm{mM}$ stock which was prepared in buffer A by sonication. (A) $\circ, 37^{\circ} \mathrm{C}$ cytosol; $37^{\circ} \mathrm{C}$ cytosol $+50 \mu \mathrm{M}$ phosphatidylglycerol. (B) $\circ, 37^{\circ} \mathrm{C}$ cytosol; $0,37^{\circ} \mathrm{C}$ cytosol $+50 \mu \mathrm{M}$ phosphatidylinositol; $\Delta,\left[{ }^{3} \mathrm{H}\right]$ phosphatidylinositol. (C) $\mathrm{O}, 37^{\circ} \mathrm{C}$ cytosol; 0 . $37^{\circ} \mathrm{C}$ cytosol $+50 \mu \mathrm{M}$ phosphatidylcholine. (D) $\circ, 37^{\circ} \mathrm{C}$ cytosol; $\odot, 37^{\circ} \mathrm{C}$ cytosol $+100 \mu \mathrm{M}$ oleic, added as phosphatidylcholine/oleic acid (1:1

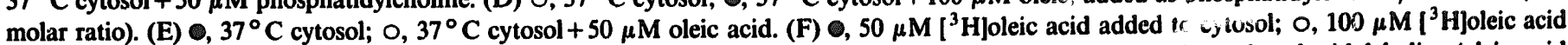
added to cytosol as phosphatidylcholine/oleic acid mixture; $\Delta,\left[{ }^{14} \mathrm{C}\right]$ phosphatidylcholine added to cytosol as phosphatidylcholine/oleic acid mixture; , phosphatidylcholine $\left./{ }^{3} \mathrm{H}\right]$ oleic acid mixture applied without cytosol (refer to right side of figure). 
basic protocol involved the dissociation of the H-Form to L-Form by incubation of cytosol at $37^{\circ} \mathrm{C}$ for $15 \mathrm{~min}$. A $1.0 \mathrm{ml}$ portion was then mixed with lipid and applied to a gradient. Another $1.0 \mathrm{ml}$ portion was applied directly to the gradient as a control. Phosphatidylglycerol (panel A) and phosphatidylinositol (panel B) caused formation of a high molecular weight aggregate which moved in the gradient to a position similar to the H-Form aggregate. The position of phosphatidylinositol in the gradient was monitored by including $\left[{ }^{3} \mathrm{H}\right]$ phosphatidylinositol in the mixture. Most of the phosphatidylinositol moved with the enzyme aggregate. The concentrations $(50 \mu \mathrm{M})$ of phosphatidylglycerol and phosphatidylinositol is sufficient to stimulate enzyme activity in cytosol preparations. Phosphatidylcholine (panel C) did not cause aggregation. However, phosphatidylcholine-oleic acid (1:1 molar ratio) formed a high molecular weight aggregate, panel D. Oleic acid also formed some aggregate but was less effective than the phosphatidylcholine/oleic acid mixtures, panel E. Oleic acid was added at $50 \mu \mathrm{M}$ because this concentration produced stimulation of cytosol activity. However, maximal activity cannot be obtained with oleic acid because concentrations above $80 \mu \mathrm{M}$ tend to cause inhibition of activity. Panel F shows the distribution of oleic acid alone or as a part of phosphatidylcholine/oleic acid mixture. The major portion of the oleic acid in both cases did not move in the gradient with the high-molecular-weight aggregate. A small and similar amount of oleic acid was present in the aggregate region of both gradients. The phosphatidylcholine part of the phosphatidylcholine/oleic acid mixture formed two peaks, one of which was in the aggregate region. All of the above results were obtained by adding the lipids to cytosol. When phosphatidylcholine/oleic acid mixture was applied to a gradient without cytosol, the lipid mixture remained at the top of the gradient. These results indicate that the phosphatidycholine/oleic acid vesicles did not remain intact in cytosol. Instead, it appears that oleic acid was removed from the vesicle, probably by binding to cytosolic proteins. These results suggest that the formation of cytidylyltransferase aggregates is not simply due to binding of cytidylyltransferase to the original phosphatidylcholine-oleic acid vesicles.

\section{Discussion}

The lowest-molecular-weight species of cytidylyltransferase which retains enzyme activity appears to be a dimer of the $M_{r} \mathbf{4 5 0 0 0}$ catalytic subunit. This form (L-Form) is essentially inactive in the absence of lipids in the assay. The molecular weight of the L-Form was previously estimated by gel-filtration chromatography to be $170000-200000[41,42,44]$. It is now apparent that this molecular weight was too high. The L-Form of cytidylyltransferase is not a globular protein, but rather it appears to be an elongated molecular with an axial ratio of 10 . Thus, gel-filtration would give an apparent higher molecular weight based on the molecular weights of standard globular proteins. The relative molecular weight of the H-Form has been estimated by gel filtration chromatography to be over $1 \cdot 10^{6}[42,50]$. The molecular weight estimated by density gradient centrifugation was on the order of 250000-300000. This discrepancy could also be due to an elongated physical shape of the aggregate. Alternatively, it may be caused by a high lipid content which could increase the relative buoyancy of the complex on density gradients. Recent studies using cross-linking reagents provided evidence that purified cytidylyltransferase exists as a dimer of $M_{r}$ 45000 subunits [53].

We reported previously that the high molecular weight form (H-Form) was the predominant form in $100000 \times g$ supernatant from adult rat lung $[41,43]$. The results in this paper verified this finding using a different method for fractionation of the cytosol. Since cytidylyltransferase is known to bind to lipid vesicles [44,51] and microsomal membranes in vitro [24,52] it is possible that the high-molecular-weight aggregate was formed during or after homogenization. The results from a variety of experimental approaches indicated that the H-Form in cell cytoplasm was not an artifact produced by homogenization. This conclusion is based on the fact that neither homogenization of lung in several different buffers or removal of pulmonary surfactant prior to homogenization changed the distribution in the cytosol. Furthermore, H-Form was present in cultured Hep G2 cells and A549 cells. These are established cells lines derived from tumors of different tissue origin. Alveolar type II cells, isolated from rat lung, also contained the H-Form as the predominant cytosolic form. Finally, permeabilization of Hep G2 cells with digitonin resulted in a rapid release of cytidylyltransferase. The released activity consisted of both $\mathbf{H}$ and $\mathrm{L}$ forms of cytidylyltransferase. Thus, the H-Form appears to be a physiologically relevant form of cytidylyltransferase which may, in some cells, be the predominant cytosolic form.

The H-Form appears to be a lipoprotein complex of the L-Form. In this context, the L-Form would be the apoprotein part of the lipoprotein. The H-Form was dissociated by Triton X-100 and by chloropromazine. Triton $\mathrm{X}-100$, is widely used to dissociate phospholipid-protein complexes in membranes. Chlorpromazine also has been reported to dissociate complexes of anionic phospholipid and protein in membranes [45-47]. The simultaneous dissociation of $\left[{ }^{3} \mathrm{H}\right]$ phosphatidylinositol and L-Form from the H-Form in Hep G2 cells provided evidence that phosphatidylinositol may be involved in the H-Form complex in these cells. The ability of phosphatidylinositol to form a high-molecular-weight complex from L-Form in lung cytosolic preparations pro- 
vided additional evidence. However, the formation of high-molecular-weight comp!exes with phosphatidylglycerol, phosphatidylcholine/oleic acid mixtures and oleic acid indicated that phosphatidylinositol was not specific. It seems likely that the addition of the appropriate lipid mixture converts the inactive apoprotein (L-Form) to an active lipoprotein (H-Form). All of the lipids or lipid mixtures which promoted the aggregation also stimulate cytidylyltransferase activity. Since the H-Form is active without the addition of lipid to the assay, the amount of H-Form in cytosols may be an indication of the existence of active cytidylyltransferase in the cytosolic pool. The exact composition of the aggregate, stoichiometric relationships between L-Form and lipid, and orientation of the enzyme in the lipid aggregate is unknown. Since there appeared to be slight differences in the sedimentation position in the gradient when different lipids were used and in different cell types, the actual size of the aggregate may depend upon the lipid composition and/or the relative amounts of L-Form and lipid. Further clarification will require a more purified preparation of the $\mathrm{H}$-Form lipoprotein.

It is now apparent that cells can contain cytidylyltransferase in three physical forms: membrane-bound, H-Form aggregate in cytoplasm and a dimer L-Form in cytoplasm. The distribution of the total activity among these forms may have regulatory significance. Both the membrane-bound form and the H-Form complex ar: active as isolated from cells. The L-Form is essentially inactive. Assuming this same property exists in the cell, the conversion of L-Form to either the H-Form aggregate or to membrane-bound form would result in an increase in cytidylyltransferase activity. Conversely, dissociation of either membrane-bound or H-Form aggregate to L-Form would lead to a decrease in cytidylyltransferase activity.

The most prevalent model for the regulation of cytidylyltransferase involves a translocation of cytosolic enzyme to membrane-bound enzyme [1]. Although translocation clearly occurs under some situations in the regulation of cytidylyltransferase activity, interconversions of cytosolic forms also may be a significant regulatory event. Indeed, the conversion of L-Form to $\mathrm{H}$ Form in addition to translocation to membrane-bound forms may explain the results in the literature which can not be explained by translocation alone. In any case, a decision concerning the regulatory mechanism requires an assessment of both the distribution of cytidylyltransferase in cytosolic forms and in membranes. Further studies are in progress to determine the relative importance of the aggregate form of cytidylyltransferase and to define the dynamics of interconversions between the subcellular forms.

\section{Acknowledgements}

This work was supported by the Veterans Administration and by NIH Grant No. HD 21992 and No. HD 02871.

\section{References}

1 Pelech, S.L. and Vance, D.E. (1984) Biochim. Biophys. Acta 779, 217-251.

2 Rooney, S.A. (1985) Am. Rev. Respir. Dis. 131, 439-460.

3 Sleight, R. and Kent, C. (1980) J. Biol. Chem. 255, 10644-10650.

4 Pritchard, P.H., Chiang, P.K., Canton, G.L. and Vance, D.E. (1982) J. Biol. Chem. 257, 636\%-6367.

5 Sleight, R. and Kent, C. (198:) J. Biol. Chem. 258, 831-835.

6 Felech, S.L., Pritchard, P.G., Brindley, D.N. and Vance, D.E. (19‘3) J. Biol. Chem. 258, 6782-6788.

7 Pelech, S.L., Cook, H.W., Paddon, J.B. and Vance, D.E. (1984) Biochim. Biophys. Acta 795, 433-440.

8 Pelech, S.L., Paddon, H.B. and Vance, D.E. (1984) Biochim. Biophys. Acta 795, 447-451.

9 Whitlon, D.S., Anderson, K.E. and Mueller, G.C. (1985) Biochim. Biophys. Acta 835, 369-377.

10 Wright, P.S., Morand, J.N. and Kent, C. (1985) J. Biol. Chem. 260, 7919-7926.

11 Maeda, M., Nishijima, M., Akamatsu, Y. and Sakakibara, Y. (1985) J. Biol. Chem. 260, 5925-5930.

12 Terce, F., Record, M., Ribbes, G., Chap, H. and Douste-Blazy. L. (1988) J. Biol. Chem. 263, 3142-3149.

13 Kolesnick, R.N. (1987) J. Biol. Chem. 262, 14525-14530.

14 Choy, P.C. (1982) J. Biol. Chem. 257, 10928-10933.

15 Pelech, S.L., Pritchard, P.H. and Vance, D.E. (1982) Biochim. Biophys. Acta 713, 260-269.

16 Sleight, R. and Kent, C. (1983) J. Biol. Chem. 258, 836-839.

17 Lim, P.H., Pritchard, P.H., Paddon, H.B. and Vance, D.E. (1983) Biochim. Biophys. Acta 753, 74-82.

18 Mock, T., Slater, T.L., Arthur, G., Chan, A.C. and Choy, P.C. (1986) Biochein. Cell Biol. 64, 413-41\%.

19 Wright, P.S. and Kent, C. (1986) Arch. Biochem. Biophys. 245, 103-113.

20 Rooney, S.A., Dynia, D.W., Smart, D.A., Chu, A.J., Ingleson, L.D., Wilson, C.M. and Gross, I. (1986) Biochim. Biophys. Acta 888, 208-216.

21 Post, M. (1987) Biochem. J. 241, 291-296.

22 Chander, A. and Fisher, A.B. (1988) Biochim. Biophys. Acta 958, 343-351.

23 Burkhardt, R., Von Wichert, P., Batenburg, J.J. and Van Golde, L.M.G. (1988) Biochem. J. 254, 495-500.

24 Weinhold, P.A., Rounsifer, M.E., Williams, S.E., Brubaker, P.G. and Feldman, D.A. (1984) J. Biol. Chem. 259, 10315-10321.

25 Chu, A.J. and Rooney, S.A. (1985) Biochim. Biophys. Acta 834, 346-356.

26 Possmayer, F., Casola, P.G., Chan, F., Macdonald, P., Ormseth, M., Wong, T., Harding, P.G.R. and Tokmakjian, S. (1981) Biochim. Biophys. Acta 664, 10-21.

27 Dobbs, L.G., Gonzales, R. and Williams, M.C. (1986) Am. Rev. Respir. Dis. 134, 141-145.

28 Batenburg, J.J., Otto-Verberne, C.J.M., TenHave-Opbroek, A.A.W. and Klazinga, W. (1988) Biochim. Biophys. Acta 960, 441-453.

29 Murthy, M.R.U. and Bharucha, A.D. (1978) Anal. Biochem. 85, 251-254.

30 Weinhold, P.A., Rounsifer, M.E. and Feldman, D.A. (1986) J. Biol. Chem. 261, 5104-5110. 
31 Miller, J.C. and Weinhold, P.A. (1981) J. Biol. Chem. 256, 12662-12665.

32 Bradford, M.M. (1976) Anal. Biochem. 72, 248-254.

33 Martin, R.G. and Ames, B.N. (1961) J. Biol. Chem. 236, 1372-1379.

34 Siegel, L.M. and Monty, K.J. (1966) Biochim. Biophys. Acta 112, 346-362.

35 Smith, M.J. (1968) in Handbook of Biochemistry (Sober, H.A., ed.), p. C-3, Chemical Rubber Company, Cleveland.

36 Tanford, C. (ed.) (1961) Physical Chemistry of Macromolecules, pp. 317-456, John Wiley \& Sons, New York.

37 Schachman, H.K. (ed.) (1959) Ultracentrifugation in Biochemistry, pp. 215-247, Academic Press, New York.

38 Laemmli, U.K. (1979) Nature 227, 680-685.

39 Snall, G.M., Imanika. T. and Lazarow, P.B. (1988) Anal. Biochem. 169, $405=409$.

40 Feldman, D.A. and Weinhold. P.A. (1987) J. Biol. Chem. 262. $9075=9081$.

41 Stern, W. Kovac, C. and Weinhold, P.A. (1976) Biochim. Biophys. Acta $441,280=293$.

42 Choy, P.C. Lim, P.H. and Vance, D.E. (1977) J. Biol. Chem. 252, 7673-7677.
43 Feldman, D.A., Dietrich, J.W. and Weinhold. P.A. (1980) Biochim. Biophys. Acta 620, 603-611.

44 Feldman, D.A., Rounsifer, M.E. and Weinhold, P.A. (1985) Biochim. Biophys. Acta 429, 429-437.

45 Bowley, M., Cooling, J., Burditt, S.L. and Brindley, D.N. (1977) Biochem. J. 165, 447-454.

46 Martin, A., Hopewell, R., Martin-Sanz, P., Morgan, J.E. and Brindley, D.N. (1986) Biochim. Biophys. Acta 876, 581-591.

47 Ito, S., Werth, D.K., Richert, N.D. and Pastan, I. (1983) J. Biol. Chem. 258, 14626-14631.

48 Pelech, S.L. and Vance, D.E. (1984) Biochim. Biophys. Acta 795, 441-446.

49 Mackall, J., Meredith, M. and Lane, M.D. (1979) Anal. Biochem. $95,270=274$.

50 Feldman, D.A., Kovac, C.R., Drangini P.L. and Weinhold, P.A. (1978) J. Biol. Chem. 253, 4980-4986.

51 Cornell, R. and Vance, D.E. (1987) Biochim. Biophys. Acta 919. $37-48$.

52. Cornell, R, and Vance, D.E. (1987) Biochim. Biophys. Acta 919, 26- 36 .

53 Cornell, R. (1989) J. Biol. Chem. 264, 9077-9082. 